Fazer bem feito

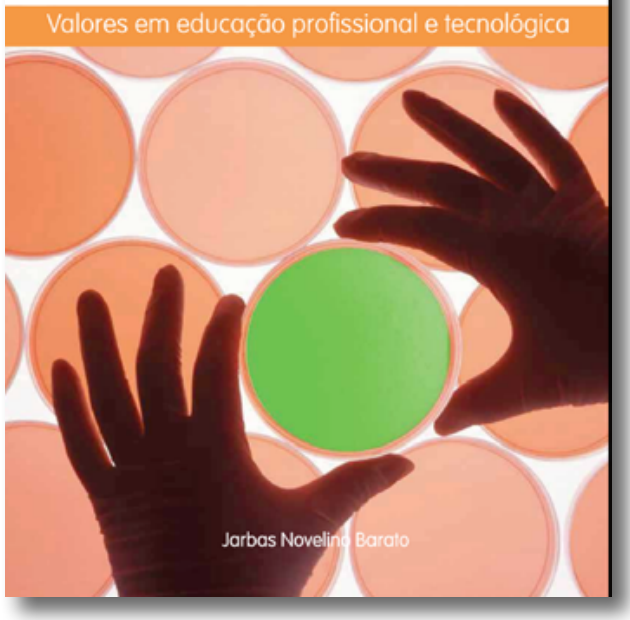

\section{RESENHA DA OBRA}

BARATO, Jarbas Novelino. Fazer bem feito: valores em educação profissional e tecnológica. Brasília, DF: UNESCO, 2015.

\title{
O trabalho educa: reflexões sobre a aprendizagem mediada por obras
}

Fazer bem feito: valores em educação profissional e tecnológica é uma obra que inspira transformações nas escolas que formam - ou pretendem formar - trabaIhadores. Professor Jarbas, pedagogo com vasta experiência na educação profissional, propõe aos educadores que se dedicam à formação de trabalhadores uma discussão não apenas necessária, mas urgente: como favorecer a construção de valores em seus estudantes? O livro é resultado de uma pesquisa cuidadosa realizada pelo autor, que visitou 33 escolas, onde observou situações de ensino e de aprendizagem, principalmente as realizadas em oficinas e laboratórios. Foi por meio dessas observações que o Professor Jarbas procurou identificar os mecanismos pelos quais trabalhadores constroem seus valores. E encontrou a resposta: no trabalho!

Infelizmente, a relação com o trabalho, no Brasil, foi construída sobre uma história marcada pela escravidão. Como disse Darcy Ribeiro (2000, p.120) em O povo brasileiro: "todos nós, brasileiros, somos carne da carne daqueles pretos e índios supliciados. Todos nós brasileiros somos, por igual, a mão possessa que os supliciou." Daí o desafio - e até mesmo a ousadia - de vislumbrar no trabalho a resposta para a construção dos valores na escola. Professor Jarbas é um dos poucos a ousar fazer essa proposição. Mas ele é rigoroso, faz isso com muita propriedade, uma vez que mostra, por meio de inúmeros exemplos, que o trabalho é terreno fértil para a construção dos valores, porque o trabalho é "uma atividade humana que, além de ser forma de produção de bens, é também forma de produção da existência" (BARATO, 2015, p. 9), sendo assim, é "uma das formas mais representativas de humanização" (BARATO, 2015, p.146). 
Inspirado em Mike Rose, autor de 0 saber no trabalho, Professor Jarbas tece uma bela narrativa enaltecendo o valor - e os valores - do trabalho, relatando o que acontece em marcenarias, cozinhas, ateliês de costura, salões de beleza e outros ambientes de trabalho que representam, na escola e no mundo do trabalho, ambientes de aprendizagem. Ele mostra que, quando engajados na construção de obras do trabalho, os estudantes desenvolvem valores, como o companheirismo e a ética do cuidado. Por isso, sua proposta é que a escola que forma trabalhadores adote uma abordagem de aprendizagem mediada pela obra.

A obra é um elemento importante na construção de identidade do trabalhador. Este se vê no que faz. Esse movimento do eu na direção da obra tem implicações de caráter ético e estético. A moral da responsabilidade na relação sujeito/obra não depende da agregação de valores externos à obra. O significado apreendido nessa relação é um valor profundo que engaja o trabalhador em seu fazer. Além disso, a relação sujeito/obra é uma experiência estética significativa que leva o trabalhador a se comprometer com o benfeito (BARATO, 2015, p. 99).

O autor destaca a importância de atos de celebração das obras do trabalho, os quais permitem que o sentimento de beleza experimentado pelo trabalhador seja compartilhado. Em educação profissional, esses momentos devem permear toda a formação, não podem se limitar a eventos esporádicos. O trabalho deve ser celebrado todos os dias, na oficina, no laboratório, na sala de aula. A educação profissional existe para formar trabalhadores, então, é preciso que, a cada dia, os estudantes futuros ou atuais trabalhadores - vejam-se como pertencentes a uma comunidade de práticas por meio das obras que produzem.

As comunidades de práticas são apresentadas pelo professor Jarbas, a partir dos trabalhos de Lave e Wenger (1991 apud BARATO, 2015), como um conceito fundamental para a educação profissional. Nessas comunidades, "o saber se constrói nas teias de relações próprias de uma corporação e isso envolve técnicas, valores e desenvolvimento de identidade" (BARATO, 2015, p. 26). Segundo Lave e Wenger (1991 apud BARATO, 2015), os aprendizes de um ofício se integram a uma comunidade de práticas, desde o primeiro dia, por meio da produção de obras. Participar da produção de obras - e não ser apenas observador desse processo - faz que o estudante se sinta parte da categoria profissional e esteja envolvido no ethos da profissão (ou seja, ao mesmo tempo o ambiente em que se produzem os valores e os valores que o constituem).

Daí surge um dos desafios apontados pelo professor Jarbas para a educação profissional: os professores, segundo o autor, precisam, eles também, fazer parte da comunidade de práticas. Contudo, em algumas das situações observadas durante sua pesquisa, evidenciou-se que mesmo professores que atuam em aulas de laboratório e oficina podem não ter intimidade com ferramentas, matérias-primas, equipamentos próprios da profissão ensinada. Moraes (2016, p. 237) também constatou, com base em estudo da legislação e das estatísticas educacionais, esse 
movimento de distanciamento dos professores da educação profissional do mundo do trabalho que se desenha já na institucionalidade de ingresso em sua carreira. E alerta para a necessidade de "construção de uma práxis pedagógica, que considere - além da titulação acadêmica - outras formas de qualificação docente, mais próximas ao mundo do trabalho."

Tal formação poderia se inspirar nos ensinamentos retirados pelo autor da sua análise dos ambientes formativos analisados. Neles, destaca-se, para começar, uma epistemologia da ação, que destoa da cultura escolar clássica, como se pode entrever nesse belo exemplo:

Os espaços da escola referência em tecnologia moveleira, assim como de algumas outras voltadas para diferentes áreas de trabalho, privilegiam a ação. Nesses ambientes, a ideia de aprender fazendo é sempre evidente, já que os prédios escolares convidam para a ação. O que modela a arquitetura de todo edifício é uma cultura do trabalho. O prédio parece dizer: "aqui se trabalha" (BARATO, 2015, p. 50).

Essa é, por sinal, uma bela surpresa que o livro do professor Jarbas reserva ao leitor: a reflexão sobre a importância que os espaços escolares têm na formação dos estudantes, a influência que um ambiente de aprendizagem e trabalho bem-concebido, planejado e equipado exerce sobre a percepção do estudante sobre si mesmo e sobre a profissão que escolheu, bem como a importância que a escola e a sociedade atribuem a essa profissão.

Outros ensinamentos proveitosos dizem respeito ainda à questão da obra do trabaIho. Em primeiro lugar, uma abordagem mediada por obras implica reconhecê-las em sua diversidade de formas e de campos profissionais. Não é tão fácil como parece. O show que vemos em alguns restaurantes, naquele que prepara a massa, por exemplo, é muito evocador. Mas o que é a obra de um técnico em Recursos Humanos? De um técnico em Logística? De um técnico em Administração? Daí a importância de analisar a atividade profissional pelo prisma da obra: o que desavisados julgariam como atividade "fragmentada" passa a revelar-se em seu valor, beleza ou importância para quem passará a usufruir da obra. Esta, por sinal, muito raramente é obra de um trabalhador só, outro mito a ser desfeito.

Assim, seguindo a lógica proposta no livro, podemos aprender algo mais sobre a natureza do trabalho de outros profissionais, mesmo fora das "oficinas", como o de uma auxiliar de escritório que refez os e-mails que tinham erros de gramática ou problemas de estilo, ou até em uma linha de produção, na qual aquele "operário" zela pelo uso não abusivo de uma máquina ou pela qualidade e beleza dos fios produzidos. A construção de valores passa, então, pelo investimento do trabalhador, que deixa sua marca, nem sempre visível imediatamente, na obra. O operário e o operar voltam a compartilhar da origem etimológica com a obra, palavra que costumamos reservar para a esfera da "cultura" (a ópera, a arte...), a qual é "distinta" (como diria Bourdieu) de tais atividades laborais tidas como "menores", algo muito comum, infelizmente, mesmo nos discursos sobre Educação Profissional. 
Estas preciosas reflexões sobre o fazer em ambientes mais próximos de comunidades de práticas - aliás, talvez, devêssemos preferir usar expressões como esta, como "mundo da profissão" ou "coletivos de trabalho", no lugar de "mundo do trabalho", que, a rigor, é tão amplo quanto o mundo tout court - nos remetem às discussões do livro sobre competências. Merece ênfase a relação muito estreita entre uma abordagem mediada por obras e uma educação baseada em competências. Apesar de ter entrado no Brasil pelo viés conteudista, que a nomeou de "pedagogia das competências", a educação por competências, mundo afora, é compreendida como "movimento educacional", uma abordagem educativa que inclui conteúdos, mas vai além deles, compreendendo a educação como processo de transformação pessoal e coletiva, baseada na premissa de que a atividade humana é motora dos saberes, que nela se articulam conhecimentos, habilidades e valores, sem separá-los. Estas três "dimensões" das competências são também parte da obra do trabalho. Nomeiam o fazer como atividade consciente, cujos processo e resultados compartilhados entre mestre e aprendiz são eventos por meio dos quais valores são incorporados. Quando se lê sobre competências, tais como descritas por Dias (2010, p.77), a seguir, como não associá-las às inúmeras passagens que narram o trabalho em oficinas no livro do Professor Jarbas?

Em situação de ensino/aprendizagem, o indivíduo aprende a identificar e a descobrir conhecimentos, a mobilizá-los de forma contextualizada. Ser competente não é realizar uma mera assimilação de conhecimentos suplementares, gerais ou locais, mas sim, compreender a construção de esquemas que permitem mobilizar conhecimentos na situação certa e com discernimento. [...] Uma abordagem por competências defende que o sujeito constrói os seus próprios saberes, numa interação afetiva que possibilita o aprender a aprender. Em contexto educativo, com os outros, o sujeito (re)descobre, (re)inventa novas possibilidades de ação que lhe permitem situar-se crítica e autonomamente na sociedade atual.

Em suma, trata-se, neste livro, de bem mais do que um passeio: mergulhamos nas entranhas da Educação Profissional, lá onde o corpo todo - junto com e além da "cabeça" - produz seus saberes. Estes, por sua vez, como Jarbas explicou magistralmente em outros livros, como Saberes do ócio ou saberes do trabalho?, não são redutíveis à divisão tradicional em um polo "prática" (sempre tido como inferior) e outro polo "teoria" (como lugar exclusivo do conhecimento), o primeiro dependendo do segundo, do qual seria "mera" aplicação. Também é no trabalho realizado nestes ambientes redescobertos que se produzem e se incorporam valores, já não mais encapsulados em pílulas de conhecimento a ser transmitido. Valores estes que nascem e se compartilham em fazeres-saberes que produzem nossa humanidade, como dizia Álvaro Vieira Pinto, longe do que este chamava de consciência ingênua, a mesma que divide formação humana de formação técnica. 


\section{Referências}

BARATO, Jarbas Novelino. Fazer bem feito: valores em educação profissional e tecnológica. Brasília, DF: Unesco, 2015. Disponível em: https://unesdoc.unesco. org/ark:/48223/pf0000233600. Acesso em: 5 abr. 2019.

DIAS, Isabel Simões. Competências em Educação: conceito e significado pedagógico. Revista Semestral da Associação Brasileira de Psicologia Escolar e Educacional, São Paulo, v. 14, n. 1, p. 73-78, jan./jun. 2010.

MORAES, Gustavo Henrique. Identidade de escola técnica vs. vontade de universidade: a formação da identidade dos Institutos Federais. 2016. 356 p. Tese (Doutorado em Educação) - Faculdade de Educação, Universidade de Brasília, Brasília, 2016.

RIBEIRO, Darcy. O povo brasileiro: a formação e o sentido do Brasil. 2. ed. São Paulo: Companhia das Letras, 2000.

ROSE, Mike. 0 saber no trabalho: valorização da inteligência do trabalhador. São Paulo: Ed. Senac São Paulo, 2007.

\section{Crislaine Gruber}

Professora no Centro de Referência em Formação e Educação a Distância do Instituto Federal de Santa Catarina (IFSC). Atua, principalmente, nas áreas de Educação Profissional, Concepção de Cursos em Educação Profissional, Análise Ergonômica do Trabalho e Didática Profissional.

E-mail: crislaine.gruber@ifsc.edu.br

\section{Olivier Allain}

Professor no Centro de Referência em Formação e Educação a Distância do IFSC. Pesquisa e leciona, principalmente, na área de Educação Profissional, mais especificamente, Epistemologia, Didática e História da Educação Profissional. E-mail: olivier@ifsc.edu.br

\section{Paulo Wollinger}

Graduação em Engenharia Elétrica pela Universidade Federal de Santa Catarina, Licenciatura para Educação Profissional pela Universidade Tecnológica Federal do Paraná, Especialização em Gestão Educacional pela Oklahoma State University - EUA, Mestrado em Engenharia Elétrica pela Universidade Federal de Santa Catarina e Doutorado em Educação pela Universidade de Brasília. Participou da construção dos Catálogos Nacionais dos Cursos de Tecnologia e Cursos Técnicos. Foi Coordenador-Geral de Regulação da Educação Tecnológica na Secretaria de Educação Profissional e Tecnológica do Ministério da Educação (Setec- MEC) e Diretor de Regulação e Supervisão da Educação Superior na Secretaria de Educação Superior (Sesu-MEC). Foi diretor de Ensino e Pró-Reitor de Ensino Substituto no IFSC. Atualmente, é docente do Centro de Referência em Formação e Educação a Distância (Cerfead) no IFSC, atuando na formação de professores para a Educação Profissional. E-mail: paulowollinger@gmail.com 